\title{
The Role of Apoptosis in Development, Tissue Homeostasis and Malignancy
}

Death from inside out 


\section{The Role of Apoptosis \\ in Development, Tissue Homeostasis and Malignancy}

Death from inside out

EDITED BY

\section{T.M. Dexter}

CRC Department of Experimental Haematology

Paterson Institute for Cancer Research

Manchester, UK

\section{M.C. Raff}

MRC Laboratory for Molecular Cell Biology

University College London

London, UK

and

\section{A.H. Wyllie}

CRC Laboratories

University Medical School

Edinburgh, $U K$ 
(C) 1995 Springer Science+Business Media Dordrecht

Originally published by Chapman \& Hall in 1995

ISBN 978-94-010-4245-1ＩSBN 978-94-011-0553-8 (eBook)

DOI 10.1007/978-94-011-0553-8

Apart from any fair dealing for the purposes of research or private study, or criticism or review, as permitted under the UK Copyright Designs and Patents Act, 1988, this publication may not be reproduced, stored, or transmitted, in any form or by any means, without the prior permission in writing of the publishers, or in the case of reprographic reproduction only in accordance with the terms of the licences issued by the Copyright Licensing Agency in the UK, or in accordance with the terms of licences issued by the appropriate Reproduction Rights Organization outside the UK. Enquiries concerning reproduction outside the terms stated here should be sent to the publishers at the London address printed on this page.

The publisher makes no representation, express or implied, with regard to the accuracy of the information contained in this book and cannot accept any legal responsibility or liability for any errors or omissions that may be made.

A catalogue record for this book is available from the British Library ANSI/NISO Z39.48-1992 (Permanence of Paper). 


\section{Contents}

$\begin{array}{lc}\text { Contributors } & \text { vii }\end{array}$

$\begin{array}{lc}\text { Preface } & \text { x }\end{array}$

Michael Dexter, Martin Raff and Andrew Wyllie

1 Death from inside out: an overview Andrew H. Wyllie

\section{DEATH IN DEVELOPMENT}

2 The ins and outs of programmed cell death during $C$. elegans development Michael O. Hengartner and H. Robert Horvitz

3 Programmed cell death in Drosophila

H. Steller, J.M. Abrams, M.E. Grether and K. White

4 Block of neuronal apoptosis by a sustained increase of steady-state free $\mathrm{Ca}^{2+}$ concentration

James L. Franklin and Eugene M. Johnson Jr

5 Apoptosis in the haemopoietic system

G.J. Cowling and T.M. Dexter

6 Programmed cell death and the control of cell survival

M.C. Raff, B.A. Barres, J.F. Burne, H.S.R. Coles, Y. Ishizaki and M.D. Jacobson

\section{REGULATION OF DEATH IN GANCER GELLS}

7 Integrated control of cell proliferation and cell death by the c-myc oncogene Gerard Evan, Elizabeth Harrington, Abdallah Fanidi, Hartmut Land, Bruno Amati and Martin Bennett

8 The role of the $\mathbf{p 5 3}$ protein in the apoptotic response

D.P. Lane, Xin Lu, Ted Hupp and P.A. Hall

\section{SIGNALS, MODULATORS AND EFFEGTORS}

9 Apoptosis regulated by a death factor and its receptor: Fas ligand and Fas

Shigekazu Nagata

10 Insights from transgenic mice regarding the role of $b c l-2$ in normal and neoplastic lymphoid cells

Suzanne Cory, Alan W. Harris and Andreas Strasser

11 Molecular mechanisms for B lymphocyte selection: induction and regulation of antigen-receptor-mediated apoptosis of mature $B$ cells in normal mice and their defect in autoimmunity-prone mice

Takeshi Tsubata, Masao Murakami, Sazuku Nisitani and Tasuku Honjo

12 Fas-based d10S-mediated cytotoxicity requires macromolecular synthesis for effector cell activation but not for target cell death M.-F. Luciani and P. Golstein 


\section{GLINIGAL APPLICATIONS}

13 Life, death and genomic change in perturbed cell cycles

Robert T. Schimke, Andrew Kung, Steven S. Sherwood, Jamie Sheriden and Rakesh Sharma

14 Apoptosis and cancer chemotherapy

J.A. Hickman, C.S. Potten, A.J. Merritt and T.C. Fisher

15 Granulocyte apoptosis and the control of inflammation

C. Haslett, J.S. Savill, M.K.B. Whyte, M. Stern, I. Dransfield and L.G. Meagher

Index 


\section{Contributors}

\section{J.M. Abrams}

Bruno Amati

B.A. Barres

\section{Martin Bennett}

J.F. Burne

H.S.R. Coles

Suzanne Cory

G.J. Cowling

T.M. Dexter

I. Dransfield

Gerard Evan

Abdallah Fanidi

T.C. Fisher

James L. Franklin

P. Golstein

M.E. Grether

P.A. Hall
Howard Hughes Medical Institute, Department of Brain and Cognitive Sciences and Department of Biology, Massachusetts Institute of Technology, Cambridge, Massachusetts 02139, USA

Biochemistry of the Cell Nucleus Laboratory, Imperial Cancer Research Fund, PO Box 123, 44 Lincoln's Inn Fields, London, WC2A 3PX

MRC Developmental Neurobiology Programme, MRC Laboratory for Molecular Cell Biology and Biology Department, University College London, London, WC1E 6BT; Current address: Department of Neurobiology, Stanford University School of Medicine, Stanford, California, 94305-5401, USA

Biochemistry of the Cell Nucleus Laboratory, Imperial Cancer Research Fund, PO Box 123, 44 Lincoln's Inn Fields, London, WC2A 3PX

MRC Developmental Neurobiology Programme, MRC Laboratory for Molecular Cell Biology and Biology Department, University College London, London, WC1E 6BT

MRC Developmental Neurobiology Programme, MRC Laboratory for Molecular Cell Biology and Biology Department, University College London, London, WC1E 6BT

The Walter and Eliza Hall Institute of Medical Research, PO Box Royal Melbourne Hospital, Victoria 3050, Australia

GRG Department of Experimental Haematology, Paterson Institute for Cancer Research, Christie Hospital (NHS) Trust, Manchester, M20 9BX

CRC Department of Experimental Haematology, Paterson Institute for Cancer Research, Christie Hospital (NHS) Trust, Manchester, M20 9BX

Respiratory Medicine Unit, Department of Medicine (RIE), University of Edinburgh Royal Infirmary, Lauriston Place, Edinburgh, EH3 9YW

Biochemistry of the Cell Nucleus Laboratory, Imperial Cancer Research Fund, PO Box 123, 44 Lincoln's Inn Fields, London, WC2A 3PX

Biochemistry of the Cell Nucleus Laboratory, Imperial Cancer Research Fund, PO Box 123, 44 Lincoln's Inn Fields, London, WC2A 3PX

Cancer Research Campaign Molecular and Cellular Pharmacology Group, The School of Biological Sciences, University of Manchester, Stopford Building (G38), Manchester M13 9PT

Department of Molecular Biology and Pharmacology, Washington University School of Medicine, 660 South Euclid Avenue, St Louis, Missouri 63110, USA

Centre d'Immunologie INSERM-GNRS de Marseille-Luminy, Case 906, 13288 Marseille Cedex 9, France

Howard Hughes Medical Institute, Department of Brain and Cognitive Sciences and Department of Biology, Massachusetts Institute of Technology, Cambridge, Massachusetts 02139, USA

Department of Pathology, University of Dundee Medical School, Dundee DD1 9SY 
Elizabeth Harrington

Alan W. Harris

C. Haslett

Michael O. Hengartner

\section{J.A. Hickman}

Tasuku Honjo

H. Robert Horvitz

Ted Hupp

Y. Ishizaki

M.D. Jacobson

Eugene M. Johnson Jr

Andrew Kung

Hartmut Land

D.P. Lane

Xin Lu

M.-F. Luciani

A.J. Merritt

L.C. Meagher

Masao Murakami

Shigekazu Nagata

Sazuku Nisitani
Biochemistry of the Cell Nucleus Laboratory, Imperial Cancer Research Fund, PO Box 123, 44 Lincoln's Inn Fields, London, WC2A 3PX

The Walter and Eliza Hall Institute of Medical Research, PO Box Royal Melbourne Hospital, Victoria 3050, Australia

Respiratory Medicine Unit, Department of Medicine (RIE), University of Edinburgh Royal Infirmary, Lauriston Place, Edinburgh, EH3 9YW

Howard Hughes Medical Institute, Department of Biology, Room 56-629, Massachusetts Institute of Technology, 77 Massachusetts Avenue, Cambridge, Massachusetts 02139, USA

Cancer Research Campaign Molecular and Cellular Pharmacology Group, The School of Biological Sciences, University of Manchester, Stopford Building (G38), Manchester M13 9PT

Department of Medical Chemistry, Faculty of Medicine, Kyoto University, Kyoto 606, Japan

Howard Hughes Medical Institute, Department of Biology, Room 56-629, Massachusetts Institute of Technology, 77 Massachusetts Avenue, Cambridge, Massachusetts 02139, USA

Cancer Research Campaign Laboratories, University of Dundee, Dundee DDl 4HN

MRC Developmental Neurobiology Programme, MRC Laboratory for Molecular Cell Biology and Biology Department, University College London, London, WC1E 6BT

MRC Developmental Neurobiology Programme, MRC Laboratory for Molecular Cell Biology and Biology Department, University College London, London, WG1E 6BT

Department of Molecular Biology and Pharmacology, Washington, University School of Medicine, 660 South Euclid Avenue, St Louis, Missouri 63110, USA

Department of Biological Sciences, Stanford University, Stanford, California 94305, USA

Biochemistry of the Cell Nucleus Laboratory, Imperial Cancer Research Fund, PO Box 123, 44 Lincoln's Inn Fields, London, WC2A 3PX

Cancer Research Campaign Laboratories, University of Dundee, Dundee, DDI 4HN

Ludwig Institute for Cancer Research, St Mary's Hospital Medical School, London W2 3PG

Centre d'Immunologie INSERM-GNRS de Marseille-Luminy, Case 906, 13288 Marseille Gedex 9, France

Cancer Research Campaign Molecular and Cellular Pharmacology Group, The School of Biological Sciences, University of Manchester, Stopford Building (G38), Manchester M13 9PT and CRC Department of Epithelial Biology, Paterson Institute for Cancer Research, Christie Hospital (NHS) Trust, Wilmslow Road, Manchester, M20 9BX

Respiratory Medicine Unit, Department of Medicine (RIE), University of Edinburgh Royal Infirmary, Lauriston Place, Edinburgh, EH3 9YW

Department of Medical Chemistry, Faculty of Medicine, Kyoto University, Kyoto 606, Japan

Osaka Bioscience Institute, 6-2-4 Furuedai, Suita, Osaka 565, Japan

Department of Medical Chemistry, Faculty of Medicine, Kyoto University, Kyoto 606, Japan 
C.S. Potten

M.C. Raff

J.S. Savill

Robert T. Schimke

Rakesh Sharma

Steven S. Sherwood

Jamie Sheridan

H. Steller

M. Stern

Andrew Strasser

Takeshi Tsubata

K. White

M.K.B. Whyte

Andrew H. Wyllie
CRC Department of Epithelial Biology, Paterson Institute for Cancer Research, Christie Hospital (NHS) Trust, Wilmslow Road, Manchester, M20 9BX

MRC Developmental Neurobiology Programme, MRC Laboratory for Molecular Cell Biology and Biology Department, University College London, London, WC1E 6BT

Division of Renal \& Inflammatory Disease, Department of Medicine, University Hospital, Nottingham, NG7 2UH

Department of Biological Sciences, Stanford University, Stanford, California 94305, USA

Department of Biological Sciences, Stanford University, Stanford, California 94305, USA

Department of Biological Sciences, Stanford University, Stanford, California 94305, USA

Department of Biological Sciences, Stanford University, Stanford, California 94305, USA

Howard Hughes Medical Institute, Department of Brain and Cognitive Sciences and Department of Biology, Massachusetts Institute of Technology, Cambridge, Massachusetts 02139, USA

Department of Respiratory Medicine, Royal Postgraduate Medical School, Hammersmith Hospital, Du Cane Road, London, W12 0NN

The Walter and Eliza Hall Institute of Medical Research, PO Box Royal Melbourne Hospital, Victoria 3050, Australia

Department of Medical Chemistry, Faculty of Medicine, Kyoto University, Kyoto 606, Japan

Howard Hughes Medical Institute, Department of Brain and Cognitive Sciences and Department of Biology, Massachusetts Institute of Technology, Cambridge, Massachusetts 02139, USA

Department of Respiratory Medicine, Royal Postgraduate Medical School, Hammersmith Hospital, Du Cane Road, London, W12 0NN

Cancer Research Campaign Laboratories, Department of Pathology, University Medical School, Edinburgh, EH8 9AG 
The past five years have witnessed a remarkable development of interest in cell death 'from inside out'. After 30 years of relative obscurity, its quantitative importance in the building and maintenance of normal tissues, the subtle strategies involved in its regulation, and its significance in the pathogenesis of diseases of major social importance are becoming clear. Moreover, because a distinct set of biological events is involved in this death, these events themselves become reasonable targets for new pharmacological agents in the treatment of cancer. The articles in this volume summarize the contents of a discussion meeting held at the Royal Society on 23 and 24 February 1994. The authors are a distinguished international group from a variety of disciplines in biology and medicine and hopefully their articles will convey something of the excitement of this fast-moving field. The three organizers are enormously indebted to all the contributors for the enthusiasm with which they delivered their talks, shared in discussion, and finally committed their contributions to these printed pages. We would also like to acknowledge the gracious way in which the Royal Society hosted the meeting, and in particular Mary Manning for making it the trouble-free and enjoyable experience that it was, and Janet Glifford and Simon Gribbin for skillfully managing the editorial processing of this volume.

Martin Raff Andrew Wyllie 